\title{
Designing silence spaces for connected communities
}

\section{RESUMO}

O presente artigo propõe uma análise sobre "comunicação verdadeira" e "pura informação". Nesse trabalho, a comunicação efetiva é abordada como sendo a complexa troca de informação de diferentes tipos de mensagens, tanto verbais quanto nãoverbais, que incluem indícios como postura corporal, gestos, entonação de voz, expressão facial etc. Além disso, interlocutores não trocam somente mensagens com informações estratégicas e conteúdo estruturado. Eles também trocam mensagens de conteúdo livre, extremamente importantes para a interação e o relacionamento entre as pessoas envolvidas.

\section{PALAVRAS-CHAVE}

- Calvino

- ambiente

- superhighway

\section{ABSTRACT}

The following article discusses the "real" communication and the question of "pure" information. In this paper the effective communication is based on a complex exchange of different kinds of messages, both verbal and non-verbal, which include information conveyed by posture, gestures, intonation, facial expression, and so on. Moreover, interlocutors do not only exchange messages with strategic information and structured data; they also exchange free content messages which are extremely important for the interaction and the relationship between the people involved environments.

\section{KEY WORDS}

- Calvino

- environment

- superhighway

\section{Federico Casalegno MIT}

$P$ alomar is the main character of the homonymous book by Italo Calvino; he is a careful and ironic observer of life and human existence in all its various aspects.

He is carefully listening to two blackbirds whistling in his garden.

He is thinking. He is looking at them. He is listening to them.

Palomar is wondering whether he is actually listening to a dialogue between them or whether every blackbird is whistling for itself and not for the other.

Furthermore, is it an exchange of questions and answers or is it that through their whistling they can give confirmation to one another (confirm their presence, their belonging to a territory, their species or their gender)?

Probably their whistling is important only because it is repeated by another whistling beak and so that they are not forgotten during the pause of silence.

Or maybe all the dialogue consists of telling the other "I am here", and the length of the pauses adds the meaning of "still". As if they were saying "I am still here, it is always me".

What if the birds talked to each other through silence, Palomar wonders.

And what if the meaning of the message was in the pause and not in the whistling?

Hunting Silent connection

We could actually raise the same question when dealing with the development of communication networks and the emerging concepts of connected communities.

New technologies are progressively improving, thus increasing the power of sending and receiving information. The costs of accessing the Internet are remarkably decreasing and the opportunity of always transmitting more and more information, sounds, images and videos is constantly improving.

Communication tools as a whole are spreading at a large scale, and more intuitive interfaces are making them more effective and easier to use (telephones, digital cameras, videos, image manipulation softwares, music and so on).

Yet here lies the paradox of technological development; as it becomes easier to spread binary information, new communication processes are yet to be found. The binary code reduces the sense of a piece of information to a series of 0 and 1, probably leading to the wrong belief that it is possible to achieve better or more effective communication processes almost mechanically. In fact, we used to refer to an information superhighway when dealing with the telecommunication revolution. It was commonly believed that in order to achieve a better communication between communities and cultures, an improved 


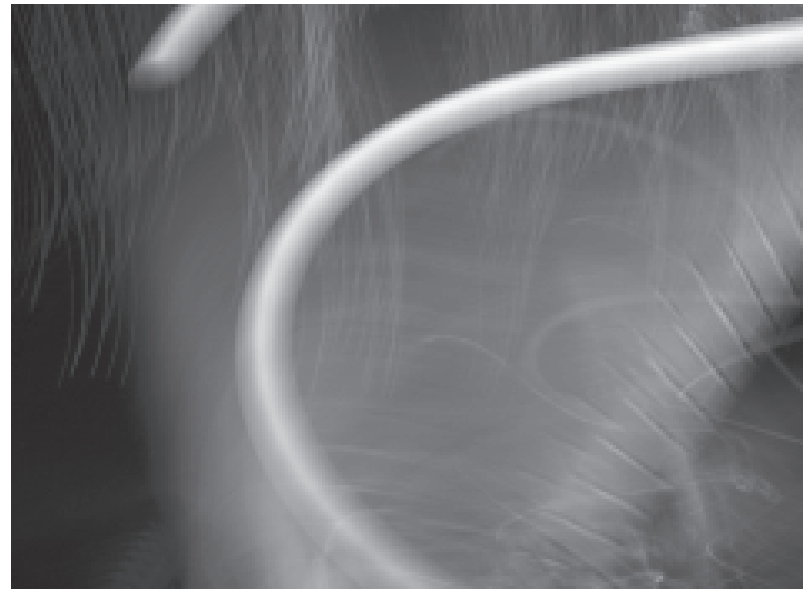

PICTURE 1

Hunting Silent connection

bandwidth or higher performance microprocessors could be enough.

Is it really true that in order to achieve a better communication between human beings, to draw distant communities and cultures nearer we need to blindly strengthen the information flow that exists between interlocutors and cultures?

Learning, for instance, is not about a mere transmission of information. Learning is an active process of appropriating and processing data and contents in which people build new visions of the world, explore, discover, think and experiment. People do not receive ideas, but create them.

"Real" communication involves much more than the mere transmission of "pure" information - important though that may be. Real, effective communication is based on a complex exchange of different kinds of messages, both verbal and non-verbal, which include information conveyed by posture, gestures, intonation, facial expression, and so on. Moreover, interlocutors do not only exchange messages with strategic information and structured data; they also exchange free content messages which are extremely important for the interaction and the relationship between the people involved environments.

The environment in which the interaction takes place plays a fundamental role in communication, since it carries important social and cultural information and helps us to spot relevant differences in cultural and social customs and behaviors.

In his essay The work of art in the age of mechanical reproduction, Walter Benjamin draws attention to ways of reproducing and transmitting the "aura" of a work of art. The aura contributes to the authenticity and uniqueness of the artwork and the wholeness of its message by reflecting the artist's vision, and by linking the artwork intractably to a here and now.

How could this feeling of uniqueness that is consumed in the moment with intangible density be transmitted, communicated or reproduced? A similar question arises in the context of new communica-

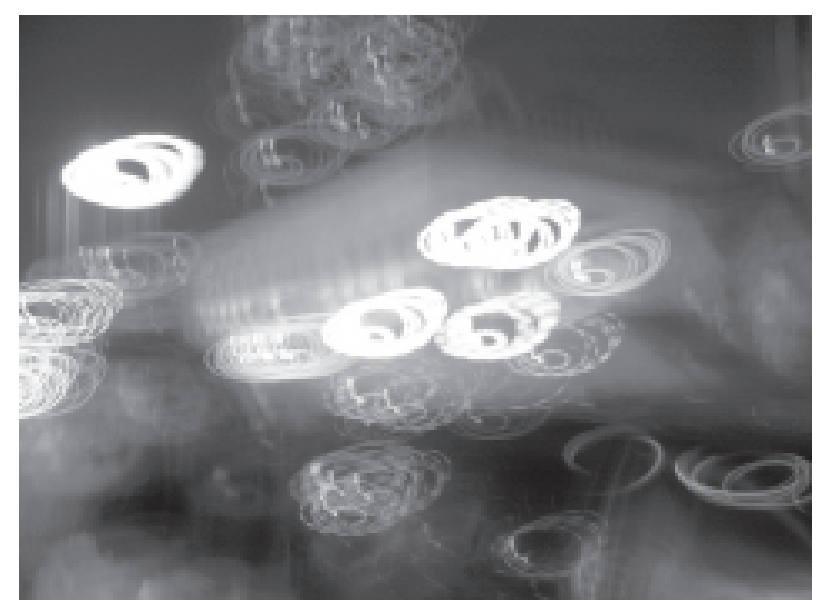

PICTURE 2

Hunting Silent connection

tion technologies. As we can access information anytime and anywhere, globally and locally, despite physical and time differences, there is a constant need to contextualize information within a "here and now". Moreover, given that technology is constantly improving and binary information can be 'easily' transmitted, it becomes increasingly necessary to transmit, or at least to think about what Benjamin defines as "aura", in other words, the synergy of the moment and the tradition, the immaterial (as well as the material), the intangible (as well as the tangible) and everything that cannot be reduced to the pure binary transmission.

What new media environments lack, and what constitutes the real challenge in designing interactive communication technologies, both in technical terms and in terms of communication dynamics, is exactly the capacity to transmit the whole content of the information, which becomes crystallized in the synergy between the information and its context, between the information and the sense that people attribute to it. Communication does not only consist of transferring strategic, planned, formal or structured information; it is also tactile and informal, visual and empathic. Contextualizing information in this way means interlacing disseminated information and enriching it with its aura, within the social and cultural context. This is the challenge that faces new media environments.

Richness of communication depends not only on the exchange of information but also on the density of the exchange - on the flavour of the information, if you like. Communication is effective only if it caters for all the elements involved in social interaction. People have been communicating for thousands of years: social interaction is based on a variety of common languages (verbal, non-verbal, gestural) and on the accretion of culture, complex rituals and social habit. To be effective, new technologies need to learn from old social dynamics. The double challenge for designers of interactive media environ- 


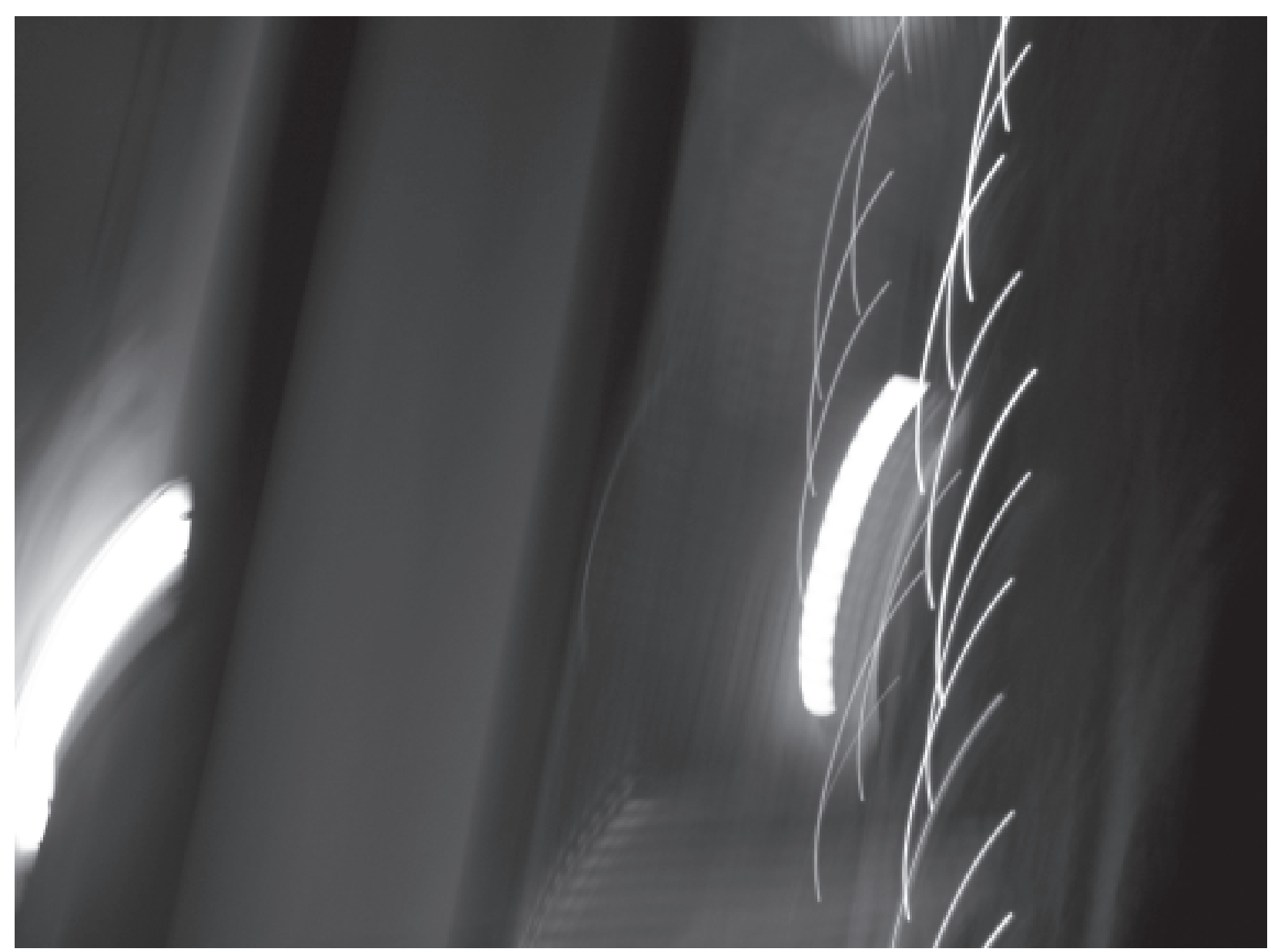

\section{PICTURE 3}

Hunting Silent connection

ments is to create systems that both help people to share information with universal meaning, and also invite the use of those aspects of communication that make up the tonality of the information - the taste of it, if you like.

Finally, the individual and social mental space for processing information is crucial: it represents a major issue of our time and therefore deserves great consideration. The development of new technologies and of emerging communication forms still follows a cybernetic or techno-centric approach: they focus on an increasingly faster and broader transmission of information, a functional and a directly operative information thus neglecting the space for comprehension. It is not a question of being prophets of doom about the acceleration of information that will end up destroying social ties, but it is a question of thinking over the importance of communication and the space for processing information.

Mr. Palomar's blackbirds communicate through silence, rather than through their whistling; in the same way, what we lack today is this silent space of dialogue, where information can take shape, sediment and take on a meaning for interlocutors and communities. And this is probably a matter of communication dynamics rather then a technological is- sue; these spaces could be technological, but they could also crystallize outside the technology sphere. After all the time we spent designing technologies that can transmit better and faster, the time has come to design silence spaces, empty environments and free moments that escape the principle of the binary code and that find in silence the richness of comprehension, exchange and shared meaning. afamecos 